\title{
Verse scored free: scansion, recording, notation.
}

One might not instinctively think that Charles Olson and Gerard Manley Hopkins should have had a great deal in common (barring, perhaps, a fondness for kingfishers). Yet both thought that new technologies of their respective days would return poetry to its source, the human voice. In "Projective Verse" Olson argues that "we have suffered from [...] manuscript, press, the removal of verse from its producer and its reproducer, the voice, a removal by one, by two removes from its place of origin and its destination" (Olson: 245). And yet, far from returning poetry straightforwardly "to the voice", whatever that would mean, Olson invokes the technology of typescript—notably the invention of the typewriter and the possibilities of the tabular page.

It is the advantage of the typewriter that, due to its rigidity and space precisions, it can, for a poet, indicate exactly the breath, the pauses, the suspensions even of syllables, the juxtapositions even of parts of phrases, which he intends. For the first time the poet has the stave and the bar a musician has had. For the first time he can, without the convention of rime and meter, record the listening he has done to his own speech and by that one act indicate how he would want any reader, silently or otherwise, to voice his work (ibid.).

What is striking about Olson's depiction of the typewriter is that, as "the personal and instantaneous recorder of the poet's work", it comes to resemble a gramophone, with the auditory technology mapped onto technologies of script. That Olson should embrace such technologies is perhaps unsurprising; it is less expected in my second example. In a letter to his brother Everard in November 1885, Gerard Manley Hopkins wrote that, "with the aid of a phonograph each phrase could be fixed and learnt by heart like a song" (Hopkins: 221). The phonograph, Hopkins suggests, the possibility of belatedly creating a tradition of verse recitation: "the phonograph may give us [this tradition], but hitherto there could be no record of fine spoken utterance" (ibid.).

For both, the voice is an "origin" only by virtue of technologies which provide prosthetics of voice, and it is through this logic of prosthesis that I will approach the question of notation and scoring the voice. The history of Hopkins's verse reception is one of readers feeling acutely aware of the singular auditory achievement these poems constitute, and yet frequently at a loss to know how best to sound these poems. Long before his invocation of the phonograph, Hopkins had felt obliged to add diacritical marks to his poems in order to instruct his reader on how to perform them: here too, we get a transformation of technologies (and technes) of script. 
Hopkins considered his 'sprung rhythm', which did not regulate the number of unstressed syllables between each stress, closer to 'natural' speech; and yet, sprung rhythm necessitated a notation system which brought about two major complications for all vocalization. Firstly, the paradox that these diacritical marks, as Meredith Martin has noted, were so far from resolving problems of how to utter the poem as to introduce yet further problems, for the simple reason that "very few readers tend to agree on how to read these signs" (Martin: 6). Michael Sprinker goes further: “Attempting to recapture the presence of spoken language, Hopkins is compelled to proliferate systems of writing. What he achieves is not the representation of spoken language, but the production of a text in the rigorous though radically unstable conception given that term by Derrida" (Sprinker: 76). What we encounter is the internal plurality and indeterminacy of voice itself, what Derrida has called "writing in the voice" (Derrrida: 150). Second is a tension between sign and symbol, as different forms of notation or performance cue. The desire to grasp vocal inflections on the page arises from a dissatisfaction with the purported arbitrariness of the alphabetic sign (which, in Saussure, treats its auditory features as "image acoustique" - a telling phrase), a preference of symbols which somehow (and it is a fraught 'somehow') resemble the sonic effects they notate. What is cast up, simultaneously, is a certain noncoincidence between the body out of which voice emanates (and which is corporealised, that is, oriented as body, through the vocal utterance itself), and the body of the mark that notates - between auditory and visual orders, but also between the phenomenality of corporeal experience and the materiality of symbol and signand at the same time, the desire for correspondence, or homology, between these two kinds of body, voice and visual mark, and (and this is crucial) of the temporal and spatial orientations of rhythm. When Olson suggests that the "typewriter ... due to its rigidity and space precisions ... can, for a poet, indicate exactly the breath, the pauses [...]", this "exactly" implies a fixed correspondence between visual and auditory, spatial and temporal, orders. And yet what we find is the very reverse of this: the speculative, almost utopian searching out a common aisthesis proceeds through those disjunctions between voice and mark which make such synthesis untenable, but which through this very impossibility set up a series of possibilities for future voicing.

The scansions and scorings of metre provide a perhaps surprisingly fertile means of approach these problematics. This is particularly the case for what has been termed the "temporal" theory of metre, which aims to grasp verse rhythms not simply at the level of alternating stressed and unstressed syllables, but by attending to the higher-order phrasings through which these rhythms unfold in time, often through analogy with 
music. Temporal theorists have long between dissatisfied with the relatively restricted vocabulary of foot metrics (iambs, dactyls, etc.), and the scansion symbols available; with music as their reference point, some theorists have turned to the notation systems that came into existence with Western diatonic harmony as inspiration for their own attempts to "score" verse rhythm. Here we find that the epistemological problems of the score, notably concerning the relation between the body that produces the sound, and the body that notates the sound, is bound up with an even broader epistemological problem, namely-how do we conceive of linguistic sound as a whole? For underlying this debate is an opposition between the focus on discrete sound units, measured in terms of binary stress-unstress oppositions, and a theory which would seek to start from higher-level phenomena such as intonation contours and phrasing. The score becomes a means of grasping such contours spatially, making visible the passage of linguistic sound through time, where it is only within time that this sound becomes a totality.

My first examples come from Joshua Steele's Prosodia Rationalis (1779). Steele is frustrated by the limitations of foot metrics, which operates through distinctions between unstress/unstress (or long/short), to be able to account of the diversity of rhythmic movement activated through prosody. In attempting to do justice to such movements, Steele turns to the still quite recently developed music notation systems of diatonic harmony, dividing up speech sound into melody and rhythmus/measure, which latter is itself divided into two components: long/short, weak/strong. This adoption from music symbols is also an adaptation, including diacritics such as the acute, grave and circumflex accents of French (although he allows himself greater liberty with circumflexes than French orthography permits). There is something salutary about this bricolage, insofar as it makes visible a tension between different but coexisting kinds of indication at work, switching between visual representations of sounds (an iconic or symbolic reference), and signs, whose visual properties are incidental to their meaning, and which refer by convention.

[figure 1, from Steele: 24] 
Insofar as Steele is making claims for language as a whole, he first directs his focus to the level of an individual syllable, and takes the exclamative 'oh' to show an expressivity beyond the the division into strong, weak, or rise-fall. ${ }^{1}$ [figure 2 , Steele, 6 ]

Yet Steele's real interest is the performance of verse. So, for instance, we can take the opening to Book IV of Alexander Pope's “Essay on Man”: “O happiness! our being's end and aim!” [Figure 3, Steele: 38] This would seem a pretty straightforward instance of the heroic line (so-called 'iambic pentameter'), made up of ten syllables, alternating stress and unstress. And yet, what seems simple from the point of view of the measure, shows itself on Steele's account to be a highly sophisticated sonic performance, comprised of rises and falls, of silences/rests, of changes in timbre, tempo, and dynamic, and even an implicit ground bass, moving from tonic to dominant! The verse melodics is thus placed within a harmonic structure; each single voicing implies further instrumentation. Attending to these details, however, Steele becomes increasingly uninterested in the verse line itself as an autonomous entity (something that sets him off from all his peers, both poets and critics). When trying to make sense of the metrically jarring opening to Paradise Lost, a poem notorious in the eighteenth century (and since!) for confounding metrists' understanding of what was permissible with the blank verse line, ${ }^{2}$ we get the following: a mapping of what would be a highly oratical rendering of it — but for which the verse line itself is apparently incidental to its voiced performance.

[figure 4, Steele 77]

Compare this with two more recent scansions of this opening line. In Metre, Rhythm and Verse Form (1996), Philip Hobsbaum scans the line thus:

$\smile \wedge|\wedge / \wedge \sim| \pi-|\smile \quad /|$

Of Man's first disobedience, and the fruit...

(Hobsbaum: 12)

Whereas Richard Cureton (2013) breaks it down as follows:

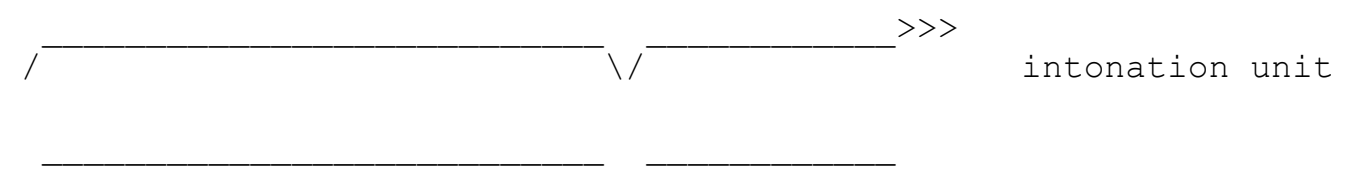

\footnotetext{
${ }^{1}$ Although, the choice of "oh" is somewhat question-begging, insofar as it functions also as vocative and as interjection, so is far from representative of all English syllables.

${ }^{2}$ On the history of Milton's reception by prosodists over the course of the eighteenth century and beyond, see Glaser.
} 


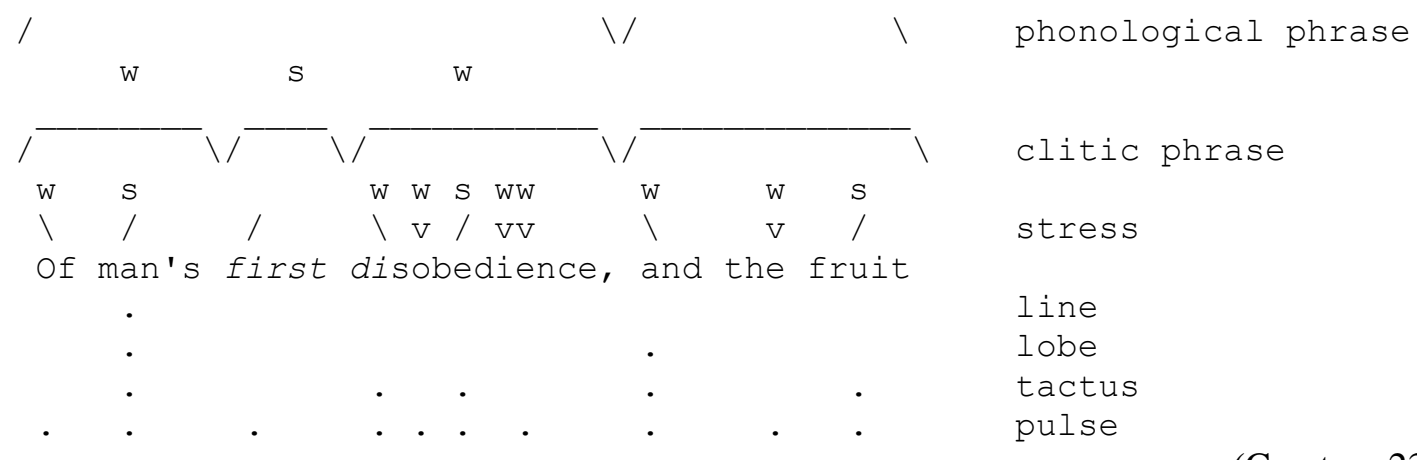

(Cureton: 231)

It is not just the proliferation of scansion symbols that should interest here, but the diverse forms of measuring taking place, and the diverse forms of listening and voicing they engender. Hobsbaum employs four differing degrees of linguistic stress: primary stress $(/)$; secondary/medium stress $(\wedge)$; tertiary stress $(\backslash)$; and weak stress ( $\smile$, whilst II denotes a pause—one response to the dissatisfaction many prosodists started to feel with the binary opposition of stress-unstress/weak-strong over the course of the twentieth century. Cureton offers three symbols: primary stress (/), secondary stress ( () and unstress (v), but also tries to map out different levels of phrasing: the "intonation unit" is divided into "phonological phrases", which themselves are made up of "clitic phrases" of individual words or short word-clusters. And, running parallel to these levels, we find the line broken up into "lobe" (which here corresponds to the phonological phrase), the "tactical beat", and the "pulse" (each individual syllable). Like many metrists, Cureton marks a distinction between the beat as a feature of poetic/musical measure, and stress, as a phonological feature; this latter is divided into weak and strong, marked by 'w' and 's'. Through all these distinctions, Cureton's scansion attempts to demonstrate the multidimensionality of rhythmic phrasing through the visual representation of its different levels on the page, thus bringing into play the homologies and disjunctions of score and performance as spatial and temporal order respectively.

Given that Cureton and Hobsbaum are writing over a century after the advent of "free verse", and Steele over a century before it, it might come as a surprise to note that it is the more recent prosodists who take the verse line as the basic unit of the scansion (Cureton even appears here to equate the verse line with the intonational unit). ${ }^{3}$ Steele anticipates the development of free verse precisely through his increased concern with

\footnotetext{
${ }^{3}$ That said, it may be that prosodists making metrical scansions after free verse are more likely to insist upon the integrity of the verse line than those for whom all verse was metrical
} 
the kinds of rhythmic patterning that do not fit the schema of stress-unstress/long-short, with the diverse possibilities of intonation, of cadence, of pause, and so forth, that "measure" does not describe, and does so to the degree that it effectively erodes the distinction between verse and prose. It is from here but one step to replace a metrical line end (indicating a metrical pause) with a line end (motivated exclusively by semantic

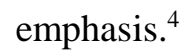

But more than this: as we shall see, it is not simply the attention to these details which anticipates free verse - it is the very model of language subtending Steele's analysis. Like many prosodists, Steele is concerned not simply with versification, but with the phonological structure of the language, and indeed with determining what the language is - English, he argues, is melodic just as much as it is syntactical or lexical. When, a century later, when American poet and prosodist Sidney Lanier also adopts musical notation in order to track the temporal-melodic structure of verse rhythm, he too wishes to provide a reappraisal of the language's overall phonology. Lanier's focus is “quantity", which contemporary metrists had been dismissing as simply an artificial adoption from the metrics of Greek and Latin verse: where the Greek iamb was "quantitative", made up of one short and one long syllable, the English iamb, it was argued, was in fact accentual, made up of one weak and one strong syllable. His point is simple, but to the point: if these syllables do not have quantity, if they do not sound within time, then we cannot discern accent in the first place. Accent thus depends on quantity. ${ }^{5}$

Yet Lanier's claims about the phonological structure of the language are characterised by a positivism quite alien to Steele, and indeed coincide with a far more literal (and literalist) analogy with music than Steele envisaged. For Lanier, the speaking voice is but one more musical instrument: "For all purposes of

\footnotetext{
${ }^{4}$ This is not to say that all free verse uses exclusively "semantic" line ends (many map on to phonological pattern, for instance); rather, that a line end might be motivated solely by semantic considerations is a resource that only free verse has at its disposal.

${ }^{5}$ Though a similar argumentation is possible in the other direction: without accent, language would never sound and hence never achieve quantity. This is what allows Antonio Scoppa to assert: "L'accent est la vie de la parole" ... "Je ne saurais imaginer un mot qui puisse s'articuler sans accent." ... "C'est par l'accent qu'on peut partager les syllabes de chaque parole en longues et en brèves." (Scoppa: 71, 73, 78). Scoppa starts his treatise with the accent in direct rejoinder to Rousseau's famous claim in his Essai sur l'origine des langues : "nous croyons avoir des accens dans nôtre langue, et nous n'en avons point" (Rousseau: 77). What is fascinating is that for Rousseau, Scoppa and Steele alike, the reference point was music, and phonological features such as speech accent and quantity had to be derived from pitch, dynamic and measure in music. The opposition of accent to quantity has been subsumed by modern phonology into a broader notion of "prominence": an amalgam of duration, pitch accent, and loudness. And yet, there remains a lack of consensus about the terminology itself, especially the word 'accent' - not least because these terms change depending on the phonology of individual languages, but also as they serve different paradigms of linguistics differently. See Kunter: esp. 60-61; and Trask: 4, definitions 3 and 4.
} 
verse, words are unquestionable musical sounds produced by a reed-instrument — the human voice" (Lanier: 49). Compared to existing musical instruments, our voices are closest to the oboe, only they are far more versatile, having at their disposal, as well as pitch, duration and intensity, what Lanier calls 'tone colour': the resources of rhyme, assonance, alliteration.

What allows for such an assertion? Lanier himself points to the experiments of Hermann von Helmholtz: "The precise proof ... that tone-color is the principle by which we discriminate the constituent sounds of speech, and the scientific analysis of the phenomenon, constitute one of the most brilliant achievemnts of modern science, which should not be mentioned without specifying the names of Charles Wheatstone, who first suggested the idea, and of Helmholtz, who demonstrated it in a series of the most beautiful studies and experiments ever made" (Lanier: 31-32). In other words, acoustic studies of the vocal material of the language lead to a revaluation of systems of prosody, here moving from the onus on "accent" to one on "tonecolor", and a shifting awareness of what verse might make of this vocal material. Helmholtz's descriptive account of physiological and acoustic process becomes the basis for a "science of verse."

Yet how to find a means of translating these advances in acoustics and physiology into the study of verse? For Lanier, the link is simple: "Print and writing are systems of notation for the tone-colors of the human speaking-voice." (Lanier: 52) This, however, leads to the very difficulty Hopkins encounters: namely, these "systems of notation" are clearly insufficient to indicate correct poetic performance, whence the need for a supplementary system of notation. Where Hopkins had adopted diacritics, Lanier borrowed from music; both brought about a conflation of sign and symbol, of conventional and iconic reference, yet in Lanier's the disjunction between visual/auditory and temporal/spatial orders becomes that much more glaring. Again, the promise of a notation moving from voice to script led only to further complicate the relation between the two, betweenthe kinds of embodiment each constitutes, and demands.

These supplements are deployed - just as in the Derridean articulation of supplementarity in Grammatology - to point us to our own natural intuitions, which had been so clouded by our subsequent education that they have been lost to us. Indeed, just as Hopkins suggested that sprung rhythm was most readily found in

\footnotetext{
${ }^{6}$ This argument is then built on in a series of essays by Cary F. Jacob, where he looks in particular at the sound production of individual vowels and the "tone-colors" thus produced. Indeed, he goes so far to suggest that "tone-colors" (or more specifically, "vowel-colors") might allow us to say of a poem that it is in a major or minor key - not meaning "that the vowels are following one another in any such sequence of pitches as would be employed by the tones of the musical scale," but rather by virtue of "the manner in which both appeal to the emotions" (Jacob: 455-456).
} 
"nursery rhymes, weather saws, and so on" (Hopkins xx: xx), Lanier too appeals to nursery rhymes in order to get beyond the calcified habits of foot metrics:

I should not call this 'bold' except for the timidity of English poetry during the last two hundred years, when it has scarcely ever dared to venture out of the round of its strictly defined iambics, forgetting how freely our folk-songs and nursery-rhymes employ rhythms and rhythmic breaks as 'Peas porridge hot', for example, or almost any verse out of Mother Goose which, though 'complex' from the standpoint of our customary rhythmic limitations, are instantly seized and co-ordinated by children and childminded nurses. (Lanier: 145$)^{7}$

Lanier's appeal to intuition and to musical notation aspire to a kind of sensus communis, legitimised by the invocation of Helmholtz's acoustics and purportedly undermined by the conventions of poetic scansion and performance over centuries, but which music can rekindle in us. Music here plays a dual role: it is noncognitive, pure experience; but its effects can also be ascribed to quantifiable physiological evidence. Lanier thus brings together the Rousseauian-Romantic model of music as subjective-yet-universal expression with the Pythagorean model, updated in Rameau's Traité de l'harmonie, of music as mathematical order: where once the overtone series provided mathematical ballast for the diatonic system of harmony at the basis of Western classical music, now it is the relations between wavelengths. This is most evident when Lanier introduces his preferred example, Tennyson's 'Break, break, break': before quoting the stanza in question, he offers a musical notation of the rhythm without its words [Figure 5, Lanier: 101], only then asserting that "every ear will accept it as a substantial reproduction of the rhythmic movement in reciting the following stanza "(Lanier: 101). Music, it would appear, lays claim to a universality of experience that will substantiate his individual intuitions about scansion.

When Lanier writes "every ear will accept this", he thinks that music has given him a means of getting beyond all reproof by virtue of possessing both an objective and a subjective universality. Music, in short, is playing an ideological function - and it is significant in this regard that the objectively and subjectively "universal" model of music is that which most closely meets the Western model of diatonic harmony (and at a historical moment when Western universality was being imposed on other cultures as part of a so-called

\footnotetext{
${ }^{7}$ We might compare this with Derek Attridge's far more pragmatic invocation of nursery rhymes, which also sees their importance in terms of our shared rhythmic resources, but does not see this as the basis for a 'science': 'For my own part, I have always had pedagogical effectiveness in mind in discussing metre and rhythm, rather than the search for human universals or the annotation of minute phonetic details. In writing about rhythm, my central question has constantly been: how can we talk about these matters in a way that makes sense to those who are not specialists? - which means, for me, how can we best tap into the considerable rhythmic capability of the ordinary man or woman, girl or boy, who heard nursery rhymes as a child, enjoys the occasional dance, and listens from time to time to popular music?' (Attridge 2010: paragraph 3).
} 
"civilizing mission"). For what Lanier has really given is not a science but an aesthetics of verse. It is not so much that claims about linguistic structure are aesthetic claims masquerading as scientific ones, more that judgments of aesthetics and phonology are not straightforwardly extricablee: each phonological claim contains a tacit aesthetic value judgment. And these value judgments then contribute to the lived history of the language, out of which arises-yes, linguistic-phonological structure.

So whilst all ears might just about agree on this particular instance of Tennyson, ${ }^{8}$ this may have more to do with these lines from Tennyson than with the nature of English phonology in general. Tennyson's poem, whilst not representative of all English verse, does metre in a very particular way, germane to Lanier's claim. But through its influence, Tennyson's poem will increasingly come to stand in as representative of English verse, and be a part, however minute, of a broader aesthetics of speech as well as verse through which the phonology of the language changes to fit its speakers. It might then be that through his invocation of these lines of Tennyson, Lanier-paradoxically enough — shows himself to be representative of a shift towards a free verse sensibility. ${ }^{9}$ As with Steele before him, the appeal to musical intuition as against metre holds preechoes of Ezra Pound's dictum, "to compose in the sequence of the musical phrase, not in sequence of a metronome" (Pound: 3); but in addition to this, the onus on silence/rest anticipates Mallarmé's description of a “rythme total, lequel serait le poëme tu, aux blancs" (Mallarmé: 367). An attentiveness to the metrical value of silences has long been a crucial tenet of 'temporal' theories of metre, placing it alongside Coventry Patmore's discussion of the centrality of catalexis to English verse (where the absence of a syllable is metrically counted), and Derek Attridge's theory of implied/virtual offbeats. ${ }^{10}$ However, when Lanier aligns these silences as "rests", through his recourse to a musical notation where the beat/offbeat distinction is far neater than in verbal art, it opens up the possibility not simply of measuring silence, but of scoring it.

But what direction should such scoring take? Lanier, like Hopkins a few years later, seeks to fix in place an 'ideal' reading: he is at once descriptivist, notating "fine utterance" and predicting how other utterances will sound, but also prescriptivist, telling us how we ought to read, using the technologies at hand for didactic purposes. Yet, with Hopkins, it transpired that this in fact led to a proliferation of readings. And there

\footnotetext{
${ }^{8}$ That said, the small discrepancies between Lanier's musical notation and his metrical notation, regarding the duration of the unstressed syllables, somewhat undermine his point.

${ }^{9}$ Lanier's own poetry, however, shows little sign of intuiting this: it remains Victorian doggerel, veering from the charming enough to the execrable.

${ }^{10}$ Patmore: 22; Attridge, 1995: 214-15, 220, 221.
} 
is no reason to believe that the same would not be the case with Lanier's notation. After all, musical staves are not records of a pre-existing auditory artefact, nor prescriptions for future sounds, but guidelines for actualising a work that will exist differently in every performance: they are the opposite of a 'record', they generate instead of dictate. Joshua Steele understood this when speaking to the celebrated actor David Garrick about his notation of his performance of Hamlet's 'To be or not to be' soliloquy. Garrick asks if this will permit other people to imitate him perfectly, and Steele replies that this would all depend on the skill of the reader imitating the performance (Steele: 54-55). In other words, the reader would have to become an actor in their turn, be drawn back into artifice.

And this is equally the case with metrical scansion. If we recall the different renderings of the first line of Paradise Lost offered by Cureton and Hobsbaum, we can see that, for all the differences in their methods for marking stress/prominence/phrasing, and the increased precision of their notation systems compared to conventional foot metrics, the scansions differ first and foremost for a far more simple reason. Cureton places his "lobes" (i.e. main stresses) on "man" and "and"-because of their place in the architecture at the line, with the initial stress of each phonological phrase, and because of their semantic prominence: the word "and" provides a hinge between the two topics of which the poem will tell (man's first disobedience, and the fruit / Of that forbidden tree) as well as providing an early insistence on continuation across syntactic and metrical boundaries which is so integral to Milton's verse art. But Hobsbaum reads the line otherwise:

The key stresses come on "first" and "fruit", a weight determined not only by rhythm but by meaning. It is this first disobedience of many that is in question, and this disobedience took place through the defiance of God's law in eating the forbidden fruit. But one cannot ignore the basic metre, any more than one can ignore the identity of the sinner-Man - and so one has to put the second most weighty kind of stress, medium rather than medium-light, on 'Man's' and on the operative part of 'disobedience'. (Hobsbaum: 12)

In other words, however sophisticated the scansion symbols to hand, this does not mean that we interpret the lines in the same way — and as long as this remains the case, each scoring will be caught between being a description of performance, and a cue for performance, caught between the body that voices and the body that sees, opening up the body that negotiates between the two.

Where might such synaesthetic scorings be found? To finish, I'll mention one set of contemporary works, which also play on the equivocation between iconic symbol and phonological sign, in order to inhabit the space between visual and auditory rhythms, so that this disjunction becomes the basis for a more heterogeneous synaesthesia. This is Jaap Blonk's Fonetische Etuden. Here Blonk employed IPA script instead of the 
Roman alphabet, as a means of exploring sound production within the mouth. But phonemes ultimately have no more basis in the mechanics of sound production than any other letter-they point to the ideal postulates of phonology, attaining their value differentially. These scores become 'studies' not just in the musical sense of training one's virtuosity, but also in explorations in the differential shifts between these signs and their interaction with the phonetic differentials at work in lips, tongue, larynx. Instead of the score providing a natural basis for sound poetry, it creates slippages and further means artifice that become, and produce, the subject of its étude.

Bibliography:

Attridge, Derek. Poetic Rhythm: An Introduction. Cambridge: Cambridge University Press, 1995.

- - - "In Defence of the Dolnik: Twentieth Century British Verse in Free Four-Beat Metre". Etudes Britanniques Contemporaines 39 (2010). Online. http://ebc.revues.org/2797

Blonk, Jaap. Fonetische Etude: Rhotic. https://media.sas.upenn.edu/pennsound/authors/Blonk/Flux-debouche/Blonk-Jaap FluxDeBouche 06-Rhotic.mp3

Cureton, Richard. "Meter and Metrical Reading in Temporal Poetics". Thinking Verse II (2012), 112-237.

Glaser, Ben. "Milton in Time: Prosody, Reception, and the Twentieth Century Abstraction of Form". Thinking Verse III (2013), 169-85.

Hobsbaum, Philip. Metre, Rhythm and Verse Form. London: Routledge, 1996.

Hopkins, Gerard Manley. The Poems of Gerard Manley Hopkins, 4th ed. W.H. Gardner and N.H. MacKenzie eds. London: Oxford University Press, 1967.

- - $\quad$ Selected Letters. Catherine Phillips ed. Oxford: Oxford University Press, 1990.

Jacob, Cary F. “On Tonality in English Verse”. The Sewanee Review 17:4, 448-457.

Kunter, Gero. Compound Stress in English: The Phonetics and Phonology of Prosodic Prominence. Amsterdam: De Gruyter, 2011.

Lanier, Sidney. The Science of English Verse. New York: Scribener, 1880. 
Mallarmé, Stéphane. Oeuvres complètes. H. Mondor and G. Jean-Aubry eds. Paris: Gallimard, Bibliothèque de la Pléiade, 1992 reprinting.

Martin, Meredith. “Hopkins's Prosody”. Victorian Poetry 49:2 (2011), 1-30.

Olson, Charles. "Projective Verse', in Collected Prose eds. Donald Allen and Benjamin Friedlander (Berkeley: University of California Press, 1997), 239-249.

Patmore, Coventry. An Essay on English Metrical Law. Mary Augustine Roth ed. Washington, D.C.: The Catholic University of America Press, 1961.

Pound, Ezra. “A Retrospect.” Literary Essays of Ezra Pound. T.S. Eliot ed. New York: New Directions, 1968. 3-14.

Rousseau, Jean-Jacques. Essai sur l'origine des langues. Charles Porset ed. Paris: A.G. Nizet, 1976.

Antonio Scoppa. Les Vrais principes de la versification Tome I. Paris: V. Courcier, 1811.

Sprinker, Michael. A Counterpoint of Dissonance: The Aesthetics and Poetry of Gerard Manley Hopkins. Baltimore: Johns Hopkins University Press, 1980.

Steele, Joshua. Prosodia Rationalis. London, J. Nichols: 1779.

Trask, R.L. A Dictionary of Phonetics and Phonology. London: Routledge, 1996. 